\title{
Ohmic Contact Characterization Using Image Processing
}

\author{
B. N. Shashikala*, B. S. Nagabhushana** \\ * M.G.R. University, Chennai, India \\ ** BMS College of Engineering, Bengaluru
}

\begin{tabular}{l}
\hline \hline Article Info \\
\hline Article history: \\
Received Apr 3, 2015 \\
Revised Jul 7, 2015 \\
Accepted Jul 28, 2015
\end{tabular}

Keyword:

GaN

Ohmic contact

Porosity

Surface morphology

\begin{abstract}
$\mathrm{The} \mathrm{Ti} / \mathrm{Al} / \mathrm{Ni} / \mathrm{Au}$ films deposited by electron beam evaporation on $\mathrm{n}$ type $\mathrm{GaN}$ was demonstrated as a suitable solution for low resistive and thermally stable contact to n-type GaN. The surface morphology of $\mathrm{Ti} / \mathrm{Al} / \mathrm{Ni} / \mathrm{Au}$ and $\mathrm{Ti} / \mathrm{Al}$ contacts were studied as a function of the annealing process conditions using image processing techniques. The algorithm was implemented using the MATLAB software. Using the algorithm made, the area occupied by the pores and porosity in the ohmic contact structures were obtained.
\end{abstract}

Copyright () 2015 Institute of Advanced Engineering and Science. All rights reserved.

\section{Corresponding Author:}

B.N. Shashikala,

Department of Electronics and Communication Engineering,

Siddaganga Institute of Technology,

B.H. Road, Tumakuru, India.

Email: shashikala.bn@rediffmail.com

\section{INTRODUCTION}

Current progress in the GaN devices requires high quality ohmic contacts. Ohmic contacts which have low resistance and a good surface morphology are required for the development of high temperature, high power and high frequency electronic devices [1], [5]. A few attempts to achieve good ohmic contacts on GaNepilayers such as Ti, Ti/Al, Ti/Al/Cu/Au, Ti/Al/Pt/Au, Ti/Al/Ti/Au, Ti/Al/Pd/Au, Ti/Al/Mo/Au, $\mathrm{Ti} / \mathrm{Al} / \mathrm{Re} / \mathrm{Au}$, etc. have been reported [6]-[14]recently. Low resistance ohmic contacts to $\mathrm{GaN}$ are of great importance, because it would lead to the improvement of device performance. The surface of theohmic contact should be ready to make an electrical connection by wire in the bonding process. The knowledge about the chemical composition of an ohmic contact will be very useful to predict the metallurgical behavior ofbond interface between the wire and the surface of the ohmic contact. Aluminum (Al) and gold $(\mathrm{Au})$ wires are commonly used in the bonding process. Investigations of ohmic contacts on GaNepilayers have indicated that the formation of TiN at the interface may be important for ohmic contact formation due to its low work function and the formation of nitrogen vacancies in the GaN below the contact layer by a reaction of Ti with $\mathrm{GaN}$. The use of Ti/Al instead of Ti decreases the contact resistivity further by forming AlN at the interface in addition to TiN.

In this work, the surface morphology of $\mathrm{Ti} / \mathrm{Al}$ and $\mathrm{Ti} / \mathrm{Al} / \mathrm{Ni} / \mathrm{Au}$ ohmic contacts to $\mathrm{n}-\mathrm{GaN}$ were examined with the use of SEM. SEM images were used to study the thin film of Ti/Al and Ti/Al $/ \mathrm{Ni} / \mathrm{Au}$ contacts to n-GaN layer using image processing techniques. In this paper various filters Disk, Gaussian, Motion, Average, unsharp, Median, Max, Min and Adaptive Wiener filters were used to remove noise from ohmic contact images and also compare results with estimation of Peak Signal Noise Ratio (PSNR). The algorithm used in this work was implemented using the MATLAB software. Using the algorithm, the area occupied by the pores and porosity in the ohmic contact structureswere obtained. 


\section{IMAGE PROCESSING TECHNIQUES ON OHMIC CONTACT}

Figure 1 shows the block diagram for finding porosity on ohmic contact surface Scanning Electron Microscope (SEM) images. Image acquisition is done using SEM. Second step is preprocessing, which involves denoising, debris removal, removal of salt and pepper noises. Since porosity is based on minute pores of nano sizes on surface, one has to carefully select filters.

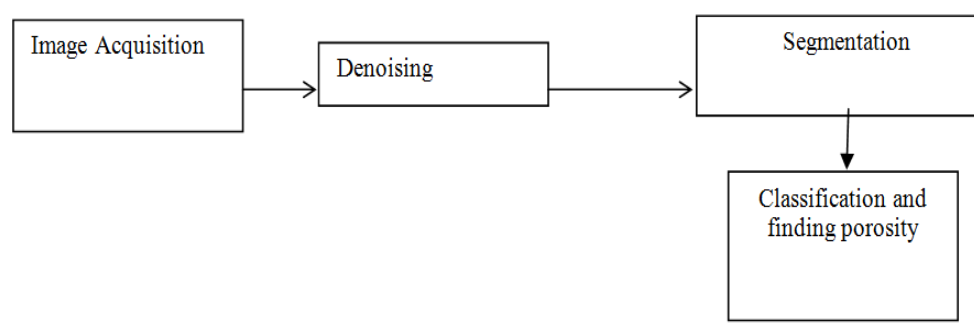

Figure 1. Block diagram for finding porosity on Ohmic contact surface SEM images

Filter is a technique that discriminates according to one or more attributes at its input, what passes through it. For example, color filters absorb light at certain wavelengths. It passes signals with frequency components in some bands and attenuate signals in other frequency bands. These techniques use operations like convolution and correlation.

Correlation is an operation which involves filtering a mask over an image. The Correlation operator $\diamond$ of filter $w(p, q)$ of image of size $(m \times n)$ with an image $I(p, q)$ is given by [15]:

$$
w(p, q) \diamond I(p, q)=\sum_{s=-a}^{a} \sum_{t=-b}^{b} w(s, t) I(p+s, q+t)
$$

Where $a_{m}$ is amask over an image, $w(p, q)$ is a filter of size $(m, n), I(p, q)$-image.

Convolution is almost same as correlation but the mask reflected about both axes. Mask is rotated by $180^{\circ}$. Convolution operator * of filter $w(p, q)$ of size $m x n$ with image $f(p, q)$ is given by:

$$
\mathrm{w}(\mathrm{p}, \mathrm{q}) * \mathrm{I}(\mathrm{p}, \mathrm{q})=\sum_{\mathrm{s}=-\mathrm{a}}^{\mathrm{a}} \sum_{\mathrm{t}=-\mathrm{b}}^{\mathrm{b}} \mathrm{w}(\mathrm{s}, \mathrm{t}) \mathrm{I}(\mathrm{p}-\mathrm{s}, \mathrm{q}-\mathrm{t})
$$

Convolution is used in time domain filtering whereas multiplication is used in frequency domain filtering. Spatial filters consider image as a grid of pixels. It directly manipulates pixels in an image. The values of neighborhood pixels are important here. This uses convolution. This changes pixels in the region of interest by its neighbor pixel values. There are three types of spatial filters used.
1) Linear
2) Non linear
3) Adaptive.

\subsection{Performance Measures}

\subsubsection{Mean Square Error (MSE)}

The MSE denotes the collective squared errorbetween the compressed and the original image, whereas PSNR denotes an amount ofthe highest error. The lower the value of MSE,the lesser the error. To compute the PSNR, the block first computes the mean-squared error using the subsequent equation:

$$
\operatorname{MSE}=\frac{1}{m n} \sum_{i=0}^{m-1} \sum_{j=0}^{n-1}[I(i, j)-K(i, j)]^{2}
$$

Where $\mathrm{m}$ and $\mathrm{n}$ are the number of rows and columns in the input images, respectively.

\subsubsection{Peak Signal-to-Noise Ratio (PSNR)}

PSNR is the evaluation standard of the reconstructed image quality, and is an important feature. The small value of PSNR means that image is poor quality. PSNR is defined as follow [16-18]: 


$$
\text { PSNR }=10 \cdot \log _{10}\left(\frac{\mathrm{MAX}_{I}^{2}}{\mathrm{MSE}}\right)
$$

Where 255 is maximum possible value that can be attained by the image signal. Ideally it is infinite. Practically it is in the range of 25 to $40 \mathrm{~dB}$.

\section{EXPERIMENTAL WORK}

The experimental procedure of this work consists of three important steps: the fabrication of ohmic contact structures, the characterization of the structures using the SEM and analysis of the images through the extraction of the more accurate morphology of the structures.

\subsection{Fabrication Procedure}

A doped n-type $\left(\mathrm{N}_{\mathrm{D}}{ }^{+}\right.$approximately $3 \times 10^{18} \mathrm{~cm}^{-3}$ by Hall measurement) GaN layer of $5 \mu \mathrm{m}$ grown by MOCVD on c-plane sapphire substrate was used for the experiment. Prior to metal deposition, a sample was cleaned in trichloroethylene (TCE) to degrease and then treated using acetone for further cleaning. The sample was then immersed in isopropyl alcohol (IPA) for complete removal of organic solvents. The sample was then well rinsed in deionized water (DI) and ready for removal of ionic contaminants and native oxide. The sample was then immersed in an equally proportioned solution of dilute $\mathrm{HCl}$ in deionized water. After this treatment for 5 minutes, the sample was rinsed again in DI water and blow dried using $\mathrm{N}_{2}$ gas. The electron beam (e-beam) evaporator was evacuated to a base pressure of about $5 \times 10^{-6}$ mbar prior to deposition. The composite metal layers were $\mathrm{Ti} / \mathrm{Al}(20 \mathrm{~nm} / 100 \mathrm{~nm})$ and $\mathrm{Ti} / \mathrm{Al} / \mathrm{Ni} / \mathrm{Au}$ $(20 \mathrm{~nm} / 100 \mathrm{~nm} / 20 \mathrm{~nm} / 100 \mathrm{~nm})$. All the metals were deposited by electron beam evaporation at $50^{\circ} \mathrm{C}$. The metal contacts were fabricated with standard photolithographic technique with a positive photoresist. The metal lift off was followed by a rapid thermal anneal (RTA) in a $\mathrm{N}_{2}$ ambient. The Ti/Al ohmic contact samples were annealed at $600^{\circ} \mathrm{C}, 700^{\circ} \mathrm{C}, 800^{\circ} \mathrm{C}$ and $900^{\circ} \mathrm{C}$ in an RTA furnace for $1 \mathrm{~min}$ in a $\mathrm{N}_{2}$ ambient. The Ti/Al/Ni/Au ohmic metallization samples were annealed at $750^{\circ} \mathrm{C}, 800^{\circ} \mathrm{C}, 850^{\circ} \mathrm{C}$, and $900^{\circ} \mathrm{C}$ in an RTA furnace for 1 min in a $\mathrm{N}_{2}$ ambient. The influence of the annealing process on the surface morphology of Ti/Al and Ti/Al/Ni/Au ohmic contacts to GaN were examined with the use of a SEM.

\subsection{Analysis of SEM Images Using Image Processing Techniques}

SEM image is saved as JPEG format. Later image is input into MATLAB environment using imread function. Images are converted into grayscale for thresholding. Various filtering techniques were used to select preprocessing method suitable for these images. PSNR is used to measure the performance of different filtering techniques. The different filtering techniques were applied on 8 images ofTi/Al and Ti/Al/Ni/Au materials, where four images of each material were taken at different temperature.Based on metric, the best suitable filtering technique was decided.

\section{RESULTS AND DISCUSSION}

Typical I-V characteristics shown in Figure 2 correspond to Ti/Al contacts annealed at different temperatures: as-deposited, $600^{\circ} \mathrm{C}, 700^{\circ} \mathrm{C}, 800^{\circ} \mathrm{C}$ and $900^{\circ} \mathrm{C}$.

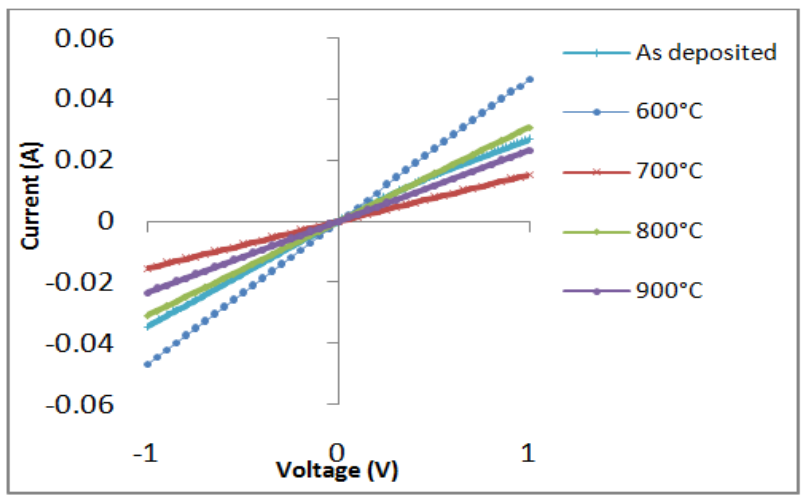

Figure 2. I-V characteristics of $\mathrm{Ti}(20 \mathrm{~nm}) / \mathrm{Al}(100 \mathrm{~nm})$ contacts on $\mathrm{n}-\mathrm{GaN}$ as deposited and after annealing at different temperatures 


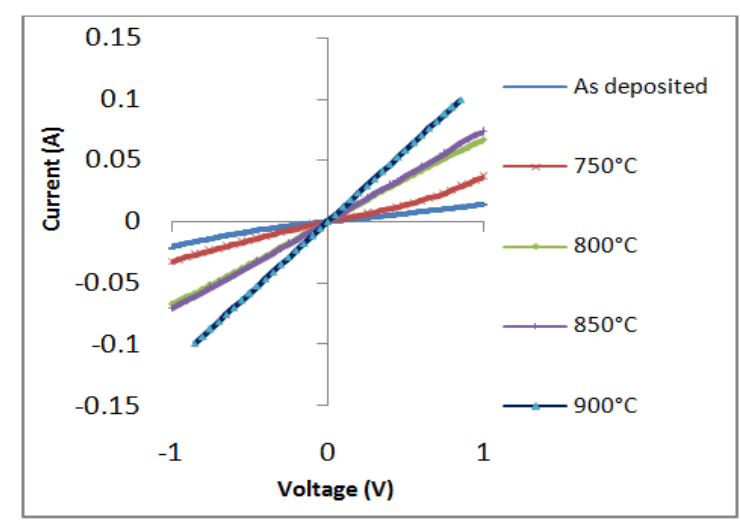

Figure 3. I-V characteristics of $\mathrm{Ti}(20 \mathrm{~nm}) / \mathrm{Al}(100 \mathrm{~nm}) / \mathrm{Ni}(20 \mathrm{~nm}) / \mathrm{Au}(100 \mathrm{~nm})$ contacts on $\mathrm{n}-\mathrm{GaN}$ as deposited and after annealing at different temperatures

Typical I-V characteristics shown in Figure 3 correspond to $\mathrm{Ti} / \mathrm{Al} / \mathrm{Ni} / \mathrm{Au}$ contacts annealed at different temperatures: as-deposited, $750^{\circ} \mathrm{C}, 800^{\circ} \mathrm{C}, 850^{\circ} \mathrm{C}$ and $900^{\circ} \mathrm{C}$. It is shown that the $\mathrm{Ti} / \mathrm{Al}$ and $\mathrm{Ti} / \mathrm{Al} / \mathrm{Ni} / \mathrm{Au}$ contacts in Figure 2 and Figure 3, respectively exhibit ohmic in their as deposited condition. It is noteworthy that the $\mathrm{Ti} / \mathrm{Al} / \mathrm{Ni} / \mathrm{Au}$ contacts show better electrical properties than the $\mathrm{T} / \mathrm{Al}$ contacts. All of the contacts showed ohmic characteristics after annealing. The decrease in the contact resistance with increasingannealing temperature is believed to be from an increase in thermal interdiffusion at the interface between the deposited metals and GaN. The resistivity of both the Ti/Al and Ti/Al/Ni/Au contacts decreases after annealing. The possible cause for decrease in the resistivity is due to the formation of a TiN layer on the $\mathrm{GaN}$ surface and associated with its growth, an excess of $\mathrm{N}$ vacancies near the TiN-GaN interface.

The specific contact resistance was determined from plots of the measured resistance versus the spacing between the CTLM pads. Measurements showed that the specific contact resistances of Ti/Al after anneal $\left(600\right.$ to $\left.900^{\circ} \mathrm{C}\right)$ varied in the range of $2 \times 10^{-4}$ to $8 \times 10^{-4} \Omega \mathrm{cm}^{2}$. Other research group has also observed similar specific contact resistances for Ti/Al contact [19]. The lowest specific contact resistance was obtained at $600^{\circ} \mathrm{C}$. The variation in the contact resistance with increasing annealing temperature is believed to be from an increase in thermal interdiffusion at the interface between the deposited metals and $\mathrm{GaN}$. Measurements showed that the specific contact resistance of Ti $/ \mathrm{Al} / \mathrm{Ni} / \mathrm{Au}$ ohmic contact after anneal $\left(750^{\circ} \mathrm{C}\right.$ to $\left.900^{\circ} \mathrm{C}\right)$ varied in the range of $2 \times 10^{-5}$ to $8 \times 10^{-5} \Omega \mathrm{cm}^{2}$. Other research groups have also observed similar specific contact resistances for $\mathrm{Ti} / \mathrm{Al} / \mathrm{Ni} / \mathrm{Au}$ contact [19]-[21]. It is noteworthy that the $\mathrm{Ti} / \mathrm{Al} / \mathrm{Ni} / \mathrm{Au}$ contact show better electrical properties than the Ti/Al contacts.

Figure 4 shows the top view SEM images of surface morphology of the Ti/Al ohmic contact after annealing at various temperatures $600^{\circ} \mathrm{C}, 700^{\circ} \mathrm{C}, 800^{\circ} \mathrm{C}$ and $900^{\circ} \mathrm{C}$ for 60 s. Figure 5 shows the top view SEM images of surface morphology of the $\mathrm{Ti} / \mathrm{Al} / \mathrm{Ni} / \mathrm{Au}$ ohmic contact after thermal annealing at various temperatures for $60 \mathrm{~s}$. An increase in annealing temperature resulted in the decrease in the density of agglomerates and leads to metal interdiffusion and alloying. This work aims to present the structural characterization of the ohmic contact on the $\mathrm{n}-\mathrm{GaN}$ based on the filtering techniques applied to SEM images. The sample images studied in this paper are of the same magnification (5000). Various image filtering techniques such as Disk, Gaussian, Motion, Average, Unsharp, Median, Max, Min and Adaptive Wiener in spatial filtering were implemented using MATLAB platform. PSNR is used to measure the performance of different filtering techniques. The filtering techniques were applied on 8 images of Ti/Aland Ti/Al/Ni/Au materials.The performance of all these image filtering techniques are analyzed for a set ofTi/Al and $\mathrm{Ti} / \mathrm{Al} / \mathrm{Ni} / \mathrm{Au}$ ohmic contact images and results are presented in Table 1 and 2, respectively.

\subsection{Metrics Values for Spatial Filters}

Table 1 shows the variation of PSNR of Ti/Al ohmic contact versus annealing temperature for Disk, Gaussian, Motion, Average, Unsharp, Median, Max, Min and Adaptive Wiener in spatial filtering techniques. Peaks at $600^{\circ} \mathrm{C}$ and $800^{\circ} \mathrm{C}$ of Ti/Al ohmic contact represent more noise is filtered in the image and has high PSNR. Valleys at $700^{\circ} \mathrm{C}$ and $900^{\circ} \mathrm{C}$ represent less noise is filtered in the image and have low PSNR. The size of the kernel filter and coefficients are fixed and cannot be adapted to a given image in Gaussian, Motion, Average and Median filters. An adaptive Wiener provides a robust solution that is adaptable to the varying noise levels of these images. Adaptive Wiener gives better PSNR than other filtering techniques for Ti/Al ohmic contact. The highest PSNR and lowest specific contact resistance was obtained at $600{ }^{\circ} \mathrm{C}$. 


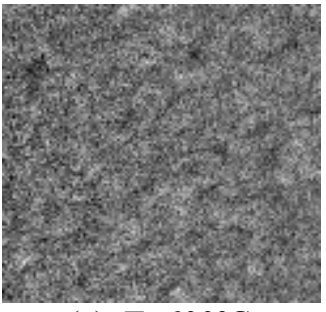

(a) $\mathrm{T}=600^{\circ} \mathrm{C}$

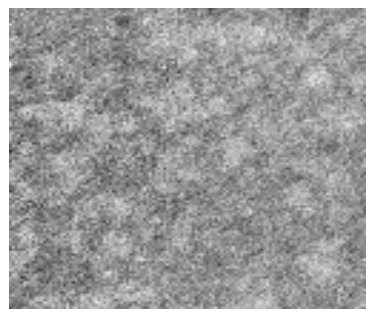

(b) $\mathrm{T}=700^{\circ} \mathrm{C}$

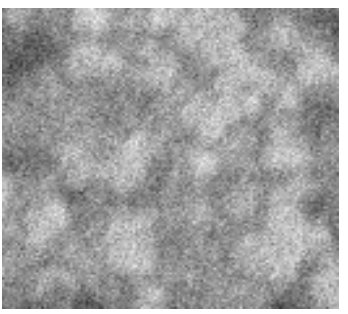

(c) $\mathrm{T}=800^{\circ} \mathrm{C}$

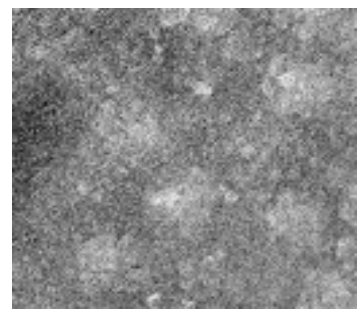

(d) $\mathrm{T}=900^{\circ} \mathrm{C}$

Figure 4. SEM images of theohmic contact $\mathrm{Ti} / \mathrm{Al}$ after thermal annealing at various temperatures for $60 \mathrm{~s}$

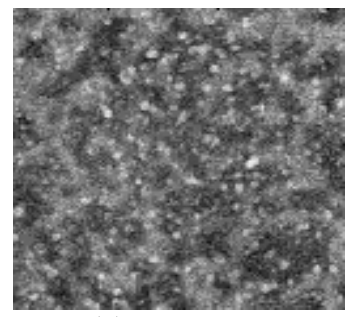

(a) $\mathrm{T}=750^{\circ} \mathrm{C}$

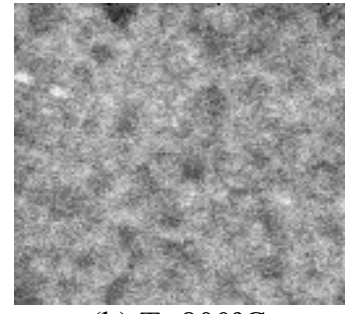

(b) $\mathrm{T}=800^{\circ} \mathrm{C}$

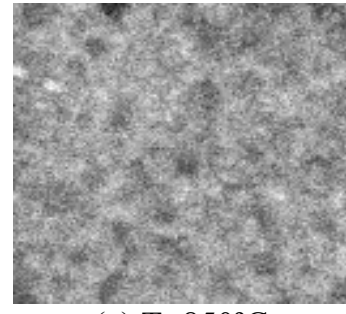

(c) $\mathrm{T}=850^{\circ} \mathrm{C}$

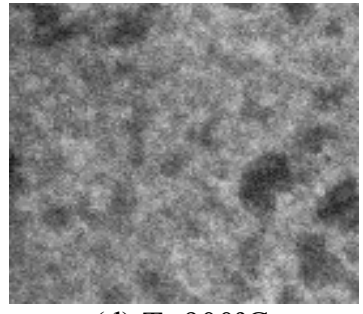

(d) $\mathrm{T}=900^{\circ} \mathrm{C}$

Figure 5. SEM images of theohmic contact $\mathrm{Ti} / \mathrm{Al} / \mathrm{Ni} / \mathrm{Au}$ after thermal annealing at various temperatures for $60 \mathrm{~s}$

Table 1. PSNR for Ti/Al ohmic contact

\begin{tabular}{cccccccccc}
\hline $\begin{array}{l}\text { Temperature } \\
\left({ }^{\circ} \mathrm{C}\right)\end{array}$ & Disk & Gaussian & Motion & Average & Unsharp & Median & Max & Min & $\begin{array}{c}\text { Adaptive } \\
\text { Wiener }\end{array}$ \\
\hline 600 & 26.50 & 27.65 & 27.04 & 26.61 & 16.55 & 27.15 & 19.35 & 20.75 & 27.25 \\
700 & 20.28 & 21.30 & 20.94 & 20.41 & 15.20 & 20.57 & 13.22 & 14.96 & 21.70 \\
800 & 24.44 & 26.22 & 25.37 & 24.85 & 19.29 & 26.07 & 17.64 & 18.85 & 26.02 \\
900 & 23.96 & 24.69 & 24.33 & 24.09 & 17.39 & 24.03 & 16.89 & 18.03 & 24.97 \\
\hline
\end{tabular}

Table 2. PSNR for $\mathrm{Ti} / \mathrm{Al} / \mathrm{Ni} /$ Auohmic contact

\begin{tabular}{cccccccccr}
\hline $\begin{array}{c}\text { Temperature } \\
\left({ }^{\circ} \mathrm{C}\right)\end{array}$ & Disk & Gaussian & Motion & Average & Unsharp & Median & Max & Min & AdaptiveWiener \\
\hline 750 & 23.70 & 25.07 & 24.56 & 23.97 & 15.33 & 24.33 & 16.72 & 18.03 & 24.87 \\
800 & 25.50 & 26.94 & 26.75 & 26.05 & 18.11 & 27.38 & 18.47 & 19.89 & 27.99 \\
850 & 25.27 & 26.56 & 26.16 & 25.54 & 16.72 & 25.42 & 18.39 & 19.21 & 26.35 \\
900 & 25.30 & 27.75 & 26.19 & 25.88 & 16.82 & 25.86 & 18.41 & 19.81 & 26.84 \\
\hline
\end{tabular}

The grains agglomeration appeared at $750^{\circ} \mathrm{C}$ in $\mathrm{Ti} / \mathrm{Al} / \mathrm{Ni} / \mathrm{Au}$ ohmic contact. As the annealing temperature was increased from $750^{\circ} \mathrm{C}$ to $900^{\circ} \mathrm{C}$ in steps of $50^{\circ} \mathrm{C}$, the agglomerates migrated on the surface and coalescence into larger agglomerates. Thus, the thermal annealing process significantly changes the morphology of the ohmic contact and influences the chemical composition of the surface of both $\mathrm{Ti} / \mathrm{Al}$ and $\mathrm{Ti} / \mathrm{Al} / \mathrm{Ni} / \mathrm{Au}$ contacts. Table 2 shows the variation of PSNR of $\mathrm{Ti} / \mathrm{Al} / \mathrm{Ni} / \mathrm{Au}$ ohmic contacts versus annealing temperature for Disk, Gaussian, Motion, Average, Unsharp, Median, Max, Min and Adaptive Wiener in spatial filtering techniques. Peaks at $800^{\circ} \mathrm{C}$ and $900^{\circ} \mathrm{C}$ of $\mathrm{Ti} / \mathrm{Al} / \mathrm{Ni} / \mathrm{Au}$ ohmic contact represent more noise is filtered in the image and has high PSNR. Valleys at $750^{\circ} \mathrm{C}$ and $850^{\circ} \mathrm{C}$ represent less noise is filtered in the image and have low PSNR. Adaptive Wienergives better PSNR than other edge detection for Ti/Al/Ni/Au ohmic contact. The highest PSNR and low specific contact resistance were obtained at $800{ }^{\circ} \mathrm{C}$ for $\mathrm{Ti} / \mathrm{Al} / \mathrm{Ni} / \mathrm{Au}$ ohmic contact.Adaptive Wienergives better PSNR for Ti/Al/Ni/Au ohmic contact than $\mathrm{Ti} / \mathrm{Al}$ ohmic contact.

As shown in Figure 4 and 5, the surface oftheohmic contacts gets quite rough due to many grooves produced on the surface after annealing at high temperature. A rough surface of ohmic contact is bad for reliability and stability. The roughness is due to the Al existing in the ohmic contact schemes, which does not react completely and is subject to melting at these high annealing temperatures. 


\subsection{Determination of OHMIC Contact Porosity on n-GaN Using Image Processing Method}

The surface study of $\mathrm{Ti} / \mathrm{Al}$ and $\mathrm{Ti} / \mathrm{Al} / \mathrm{Ni} / \mathrm{Au}$ films deposited by electron beam evaporation on $\mathrm{n}$ type GaN were characterized by employing SEM. SEM images of the ohmic contacts were used to determine the porosity. The surface morphology of $\mathrm{Ti} / \mathrm{Al} / \mathrm{Ni} / \mathrm{Au}$ and $\mathrm{Ti} / \mathrm{Al}$ contacts were studied as a function of the annealing process conditions using image processing techniques. Then various segmentation techniques were used to distinguish pores on the surface image.

Table 3. Percentage of white and black pores on Ti/Al ohmic contact

\begin{tabular}{ccc}
\hline Temperature $\left({ }^{\circ} \mathrm{C}\right)$ & White & Black \\
\hline 600 & 81.06 & 18.94 \\
700 & 78.81 & 21.19 \\
800 & 72.02 & 27.98 \\
900 & 60.37 & 39.63 \\
\hline
\end{tabular}

Table 4. Percentage of white and black pores on $\mathrm{Ti} / \mathrm{Al} / \mathrm{Ni} / \mathrm{Au}$ ohmic contact

\begin{tabular}{ccc}
\hline Temperature $\left({ }^{\circ} \mathrm{C}\right)$ & White & Black \\
\hline 750 & 69.70 & 30.30 \\
800 & 73.96 & 26.04 \\
850 & 62.03 & 37.97 \\
900 & 70.00 & 30.00 \\
\hline
\end{tabular}

Porosity is defined as the fraction of the bulk sample area $\mathrm{A}$ that is not occupied by solid matter. If the area of the solids is denoted by $A_{s}$, and the pore area as $A_{p}=A-A_{s}$, then porosity $=\left(A_{p} / A\right)$. The pores are in black and the surface of the thin film is in white. The analysis of the binarized image is based on the digitalization of each pore of the thin film surface followed by the measurement of the pore area. The major effects of annealing process are to promote recrystallization leading to grain growth and grain boundary passivation. The effect of annealing under different temperature on the distribution of these thin films pores and the percentage porosity of the white and black pores are as shown in the Table 3 and 4 for Ti/Al and $\mathrm{Ti} / \mathrm{Al} / \mathrm{Ni} / \mathrm{Au}$ ohmic contacts, respectively. The porosity of white areas on the surface of $\mathrm{Ti} / \mathrm{Al}$ film decreases as the annealing temperature increases and the black areas increases as the annealing temperature increases. The porosity of white areas on the surface of $\mathrm{Ti} / \mathrm{Al} / \mathrm{Ni} / \mathrm{Au}$ film is highest at $800^{\circ} \mathrm{C}$ annealing temperature and the porosity of the black areas is lowest at $800^{\circ} \mathrm{C}$. The proportion of porosity on the surface of ohmic contact varies with annealing temperature because the annealing works on recrystallized grains of the thin films so the white areas are less and which represents the surface of the ohmic contact. On the other hand, the black areas aregrowing which represent pores, cracks, and defects on the surface of the ohmic contact.

\section{CONCLUSION}

$\mathrm{Ti} / \mathrm{Al}$ and $\mathrm{Ti} / \mathrm{Al} / \mathrm{Ni} / \mathrm{Au}$ ohmic contacts were deposited on n-type $\mathrm{GaN}$ and annealed at various temperatures for 60s have been compared in terms of specific contact resistance and surface morphology. The variations of PSNR of $\mathrm{Ti} / \mathrm{Al}$ and $\mathrm{Ti} / \mathrm{Al} / \mathrm{Ni} / \mathrm{Au}$ ohmic contacts versus annealing temperature for Disk, Gaussian, Motion, Average, Unsharp, Median, Max, Min and Adaptive Wiener in spatial filtering techniques were studied. Gaussianand Adaptive Wienergives better PSNR for Ti/Al and Ti/Al/Ni/Au ohmic contacts. Adaptive Wiener gives better PSNR for $\mathrm{Ti} / \mathrm{Al} / \mathrm{Ni} / \mathrm{Au}$ ohmic contact than $\mathrm{Ti} / \mathrm{Al}$ ohmic contact. The proportion of porosity on the surface of $\mathrm{Ti} / \mathrm{Al}$ and $\mathrm{Ti} / \mathrm{Al} / \mathrm{Ni} / \mathrm{Au}$ films decreases as the annealing temperature increases because the annealing works on the recrystallized grains of the thin films. Thus $\mathrm{Ti} / \mathrm{Al} / \mathrm{Ni} / \mathrm{Au}$ ohmic contacts may be preferred for high temperature and high power devices on GaN.

\section{ACKNOWLEDGEMENT}

The authors would like to thank the professors and staff members of the Center of Excellence in Nanoelectronics (CEN) for their support during the fabrication process. The experiments in this paper were carried out at Indian Institute of Technology Bombay and Indian Institute of Science Bangalore under the Indian Nanoelectronics Users Program. 


\section{REFERENCES}

[1] S. Sundeep and Dr. G. Madhusudhan Rao, "Modelling and Analysis of Custom Power Devices for Improve Power Quality," International Journal of Electrical and Computer Engineering, Vol. 1, No. 1, pp. 43-48, 2011.

[2] S. M. Mahaei, M. TarafdarHagh, and K. Zare, "Modelling FACTS Devices in Power System State Estimation," International Journal of Electrical and Computer Engineering, Vol. 2, No. 1, pp. 57-67, 2012.

[3] Subramaniam Arulkumaran, et al., "Record-low contact redistance for InAlN/AlN/GaN high electron mobility transistors on Si with non-gold metal," Japanese Journal of Applied Physics, Vol. 54, pp. 04-12, 2015.

[4] X. Zhang, A. Saxler, P. Kung, M. Razeghi, D. Walker, and J. Xu, "AlGaN Ultraviolet photoconductors grown on Sapphire," Applied Physics Letters, Vol. 68, No. 15, pp. 2100-2101, 1996.

[5] R. Stall, S. Liang, Y. Lu, C. Joseph, I. Ferguson, C. A. Tran, R. F. Karlicek, and Z. C. Feng, "GaN and AlGaN metal-Semiconductor-metal Photodetectors," Materials Science and Engineering, Vol. 50, No. 1, pp. 311-314, 1997.

[6] N. A. Papanicolaou, M. V. Rao, J. Mittereder, and W. T. Anderson, "Reliable Ti/Al and Ti/A1/Ni/Au contacts to ntype GaN formed by vacuum annealing," Journal of Vacuum Science \& Technology B, Vol. 19, pp. 261-267, 2001.

[7] M. E. Lin, Z. Ma, F. Y. Huang, Z. F. Fan, L. H. Allen, and H. Morkoc, "Low resistance ohmic contacts on wide band-gap GaN," Appl. Phys. Letters, Vol. 64, No. 8, pp. 1003-1005, 1994.

[8] Cong Wang and Nam-Young Kim, "Electrical characterization and nanoscale surface morphology of optimized Ti/Al/Ta/Au ohmic contact for AlGaN/GaN HEMT," Nanoscale Research Letters, Vol. 7, No. 1, pp. 107, 2012.

[9] V. Rajagopal Reddy and C. K. Ramesh, "Low-resistance ohmic contacts to n-type GaN using Ti/Al/Re/Au multilayer scheme," Journal of Optoelectronics and Advanced Materials, Vol. 6, No. 1, pp. 177-182, 2004.

[10] H. C. Lee, J. W. Bae, and G. Y. Yeom, "Thermally Stable Ti/Al/W/Au Multilayer Ohmic Contacts on n-type GaN," Journal of the Korean Physical Society, Vol. 51, No. 3, pp. 1046-1049, 2007.

[11] Deepak Selvanathan, Fitih M. Mohammed, Asrat Tesfayesus, and Ilesanmi Adesida, "Comparative study of $\mathrm{Ti} / \mathrm{Al} / \mathrm{Mo} / \mathrm{Au}, \mathrm{Mo} / \mathrm{Al} / \mathrm{Mo} / \mathrm{Au}$, and $\mathrm{V} / \mathrm{Al} / \mathrm{Mo} / \mathrm{Au}$ ohmic contacts to $\mathrm{AlGaN} / \mathrm{GaN}$ heterostructures," Journal of Vacuum Science \& Technology B, Vol. 22, No. 5, pp. 2409-2416, 2004.

[12] L. Dobos, B. Pecz, L. Toth, Zs. J. Horvath, Z. E. Horvath, A. Toth, E. Horvath, B. Beaumont, and Z. Bougrioua, "Metal contact to n-GaN," Applied Surface Science, Vol. 253, pp. 655-661, 2006.

[13] Liu Y, et al., "Mechanisms of Ohmic Contact Formation and carrier Transport of Low Temperature Annealed $\mathrm{Hf} / \mathrm{Al} / \mathrm{Ta}$ on $\mathrm{In}_{0.8} \mathrm{Al}_{0.82} \mathrm{~N} / \mathrm{GaN}-$ on-Si," ECS Journal of Solid State Science and Technology, Vol. 4, No. 2. pp. 30-35, 2015.

[14] Su Jin Kim, Tae Yang Nam, and Tae Geun Kim, "Low-Resistance Nonalloyed Ti/Al Ohmic Contacts on N-Face nType GaN via an Plasma Treatment," IEEE Electron Device Letters, Vol. 32, No. 2, pp. 149-151, 2011.

[15] R. C. Gonzalez and R. C. Woods, Digitsl Image Processing, $3^{\text {rd }}$ edition, 2008.

[16] Z. Wang, A. C. Bovik, H. R. Sheikh, and E. P. Simoncelli, "Image quality assessment from error visibility to structural similarity,” IEEETrans. Image Process., Vol. 13, No. 4, pp. 600-612, 2004.

[17] H. R. Sheikh and A. C. Bovik, "Image information and visual quality," IEEE Trans. Image Process., Vol. 15, No. 2, pp. 430-444, 2006.

[18] Zhou Wang, Alan C. Bovik, “A Universal Image Quality Index,” IEEE Signal Processing Letters, Vol. 9, No. 3, pp. $81-84,2000$.

[19] N. A. Papanicolaou, M. V. Rao, J. Mittereder, and W. T. Anderson, "Reliable Ti/Al and Ti/Al/Ni/Au ohmic contacts to n-type GaN formed by vauum annealing," Journal of Vacuum Science \& Technology B, Vol. 19, No. 1, pp. 26167, 2001.

[20] Z. X. Qin, Z. Z. Chen, Y. Z. Tong, X. M. Ding, X. D. Hu, T. J. Yu, and G. Y. Zhang, "Study of Ti/Au, Ti/Al/Au, and Ti/Al/Ni/Au ohmic contacts to n-GaN," Applied Physics A, Vol. 78, pp. 729-731, 2004.

[21] B. Jacobs, M. C. J. C. M. Kramer, E. J. Geluk, and F. Karouta, "Optimisation of the Ti/Al/Ni/Au ohmic contact on AlGaN/GaN FET structures,” Journal of Crystal Growth, Vol. 241, pp. 15-18, 2002. 